\title{
Espacio, poder y desarrollo: intervenciones públicas en la Argentina de principios del siglo XXI*
}

\author{
Ariel Óscar GARCÍA \\ Centro de Estudios Urbanos y Regionales \\ CONICET (Argentina) \\ arielgarcia@conicet.gov.ar
}

Recibido: 14-11-2014

Aceptado: 23-01-2015

\section{RESUMEN}

En este trabajo ofrecemos un marco teórico-interpretativo sobre las nociones de espacio y poder en las políticas de desarrollo, considerando la gestión pública argentina de principios de siglo XXI. El objetivo es conocer la relación entre las nociones de poder, espacio y desarrollo a partir de un análisis de las burocracias. A través de una revisión y sistematización bibliográfica, apelamos a dichas nociones para interpelar a dos políticas de desarrollo: el Programa de Atención a Grupos Vulnerables y el Programa Nacional de Microcrédito para la Economía Social. Nuestra hipótesis es que los aportes conceptuales sobre las nociones de poder, espacio y desarrollo suelen abordar parcialmente las problemáticas de las políticas públicas en países periféricos a principios de siglo XXI. En la medida que las burocracias estatales ligadas al desarrollo actúan a través de intervenciones que responden a cosmovisiones diversas y/o contradictorias resulta necesario un debate conceptual que clarifique posiciones y alumbre posibilidades de gestión pública.

Palabras clave: espacio; poder; desarrollo; políticas públicas; burocracias.

\section{Space, Power and Development: Public Interventions in Argentina in early $21^{\text {st }}$ Century}

\begin{abstract}
Based on an analysis of Argentinean public governance in the early $21^{\text {st }}$ century, this article offers an interpretative framework on the notions of space and power in development policies. The goal is to understand the relationship between notions of power, space and development through an analysis of bureaucracies. The revision of the specialized literature helps address two specific development policies: "Programa de Atención a Grupos Vulnerables" and "Programa Nacional de Microcrédito para la Economía Social". Our hypothesis is that the literature conceptualizes power, space and development in a manner that fails to account for specific problematics of how peripheral countries deal with public policies in the early $21^{\text {st }}$ century. In so far as state bureaucracies responsible for developmental policies base their interventions on
\end{abstract}

* El autor agradece los atinados comentarios de los evaluadores, a partir de los cuales se han logrado mejoras en el desarrollo del texto y en la exposición de ideas. 
criteria that are pervaded by different and / or contradictory worldviews, our argument is that a conceptual debate should help clarify positions and suggest alternative models of governance.

Key words: space; power; development; public policies; bureaucracies.

\title{
Espaço, poder e desenvolvimento: intervenções públicas na Argentina no começo do século XXI
}

\begin{abstract}
RESUMO
Oferecemos neste artigo um quadro teórico-interpretativo sobre as noções de espaço e poder nas políticas de desenvolvimento, considerando a gestão pública argentina de inicios do século XXI. O objetivo é conhecer a relação entre as noções de poder, espaço e desenvolvimento a partir de uma análise das burocracias. Após uma revisão e sistematização da bibliografia pertinente, discutimos estas noções interpelando duas políticas de desenvolvimento: o Programa de Atenção a Grupos Vulneráveis e o Programa Nacional de Microcrédito para a Economia Social. Nossa hipótese é que os aportes conceituais sobre as noções de poder, espaço e desenvolvimento abordam somente parcialmente as problemáticas das políticas públicas nos países periféricos no início de século. Tendo em vista que as burocracias estatais vinculadas ao desenvolvimento atuam através de intervenções que remetem a cosmovisões diversas e/ou contraditórias, torna-se necessário um debate conceitual que esclareça as posições e ilumine possibilidades de políticas públicas.
\end{abstract}

Palavras-chave: espaço; poder; desenvolvimento; políticas públicas; burocracias.

REFERENCIA NORMALIZADA

García, Ariel Oscar (2014) "Espacio, poder y desarrollo: intervenciones públicas en la Argentina de principios del siglo XXI". Geopolítica(s). Revista de estudios sobre espacio y poder, vol. 5, núm. 2, 207-230.

SUMARIO: Introducción. 1. Espacio. 2. Poder. 3. Desarrollo. 4. Políticas de desarrollo: alcances y limitaciones. Reflexiones finales. Bibliografía.

\section{Introducción}

En este trabajo ofrecemos un marco teórico-interpretativo sobre las nociones de espacio y poder en las políticas ${ }^{1}$ de desarrollo, considerando la gestión pública

\footnotetext{
${ }^{1}$ Aquí asumimos la definición de política como "un comportamiento propositivo, intencional, planeado [...]. Se pone en movimiento con la decisión de alcanzar ciertos objetivos a través de ciertos medios: es una acción con sentido. Es un proceso, un curso de acción que involucra todo un conjunto complejo de decisiones y operadores. La política también es una actividad de comunicación pública. La política real, en tanto lucha por el poder en función de intereses y ventajas, se expresa y efectúa en el proceso de elaboración de políticas. [...]". La política como finalmente lo señala Luis Aguilar Villanueva es entonces un resultado de enfrentamientos y compromisos, de competiciones y coaliciones de conflictos y transacciones convenientes (Ruíz López y Cádenas Ayala, 2004: 1).
} 
argentina de principios de siglo XXI. A través de una revisión y sistematización bibliográfica, partimos de la necesidad de transitar el camino de redescubrir las nociones de espacio, poder y desarrollo para interpelar a dos políticas de desarrollo: el Programa de Atención a Grupos Vulnerables (PAGV) y el Programa Nacional de Microcrédito para la Economía Social (PMES). Lo hacemos entendiendo que el sinuoso derrotero de la planificación regional que se está transitando en la Argentina de principios de siglo XXI incluye variadas aspiraciones y cosmovisiones, aunque en el mismo suele estar ausente el debate sobre qué se comprende por dichas nociones ${ }^{2}$.

Nuestra hipótesis es que los aportes conceptuales sobre espacio, poder y desarrollo suelen abordar solo parcialmente las problemáticas de las políticas públicas en países periféricos a principios de siglo XXI. Esto sucedería por un desconocimiento/subestimación de las prácticas que abarcan el diseño y la implementación de dichas políticas, en las que las burocracias estatales: i) son sujetos intervinientes con intereses propios (sostenerse, reproducirse a través de la construcción del objeto de intervención, ampliar su influencia sobre otros sujetos, construir o incidir en la agenda pública, etc.); ii) se encuentran atravesadas por intereses privados con capacidad de incidir en las etapas de formulación e implementación - usualmente se trata de empresas con significativa participación económica en el sector que es objeto de regulación-; iii) dicen perseguir y defender la salvaguarda del interés general - aunque el mismo usualmente implique consignas difusas y cambiantes-.

Nuestro objetivo es conocer la relación entre las nociones de poder, espacio y desarrollo en las políticas públicas a partir de un análisis de las burocracias. Concebimos a las mismas como el resultado de los contenidos de las políticas públicas ${ }^{3}$ que implementan a partir de las sucesivas tomas de posición asumidas desde el Estado por acción u omisión frente a cuestiones de la agenda pública (Oszlak, 2006). Tales tomas de posición suponen el beneficio o perjuicio de unos u otros sujetos sociales, en resoluciones temporal y espacialmente variables. Por esto, consideramos que la capacidad - o incapacidad - de aquéllos de influir sobre la burocracia estatal resulta una dimensión explicativa de las distintas configuraciones que ella

\footnotetext{
${ }^{2}$ A nuestro juicio, este hecho resulta relevante, debido a que los resultados de un diseño de intervención pueden variar en función de qué preceptos lo fundamenten y sustenten. Más aún, sus consecuencias pueden ser inciertas si sus conceptos obedecen más a la repetición de lugares comunes que a una estrategia deliberada a través de la cual transformar los escenarios sobre los cuales se pretende intervenir.

${ }^{3}$ Definimos a las políticas públicas como "el conjunto de actividades de las instituciones de gobierno, actuando directamente o a través de agentes, y que van dirigidas a tener una influencia determinada sobre la vida de los ciudadanos". Pallares señala: las Políticas Públicas deben ser consideradas como un "proceso decisional", un conjunto de decisiones que se llevan a cabo a lo largo de un plazo de tiempo" (Ruíz López y Cádenas Ayala, 2004: 1). Entendemos a las políticas de desarrollo como aquellas intervenciones inspiradas en la noción de desarrollo, usualmente tendientes a viabilizar la inversión y reproducción de capital y a atender sus efectos perniciosos sobre los grupos vulnerables.
} 
adquiere a lo largo de la historia. Entonces, como institucionalización del Estado en una organización social capitalista, Oszlak (1976) halla que la burocracia estatal cumpliría tres roles: i) sectorial, al asumir la representación de sus intereses propios como un actor más de la sociedad; ii) mediador, al expresar su función de promotora o garante de los intereses de los sectores económicamente dominantes; y iii) infraestructural, al buscar el cumplimiento de los objetivos que responden al interés general de la sociedad en su conjunto. Una síntesis de estos tres roles puede hallarse en la noción de burocracia como "arena de conflicto" (Oszlak, 2006).

El trabajo se organiza en seis apartados. Luego de esta introducción, se presentan tres apartados conceptuales, en los que sucesivamente se plantean las nociones de espacio, poder y desarrollo en relación a intervenciones públicas. A continuación se describen las dos políticas de desarrollo seleccionadas a la luz de los aportes conceptuales previamente exhibidos. Y, por último, se exponen las reflexiones finales.

\section{Espacio}

El espacio como categoría analítica ha sufrido cambios a través del tiempo. Discutimos que el espacio esté destinado a ser reconocido solo como una dimensión de lo social, dado que a través de esa afirmación tan solo la mitad del argumento ha sido desarrollado (García y Rofman, 2013: 102). Actualmente resulta extendida la idea de que éste es una construcción social, aunque se desestima que los procesos sociales se producen - condicionan, legitiman y un extenso etcétera- en el espacio. Si el espacio fuera solo un resultado, las distribuciones geográficas serían meras secuelas de los procesos sociales. Así, una de las consecuencias más significativas de este desconocimiento radica en que recurrentemente los estudios sociales tienden a abrevar en las dimensiones temporales, aunque de su análisis se desprende que el "mundo pareciera caber en la cabeza de un alfiler" (Massey, 2012: 100). De tal modo, aspectos centrales como la localización, la distancia, los movimientos y las distribuciones, suelen ser relegados como si se tratara de acontecimientos sin potencia explicativa. Coincidimos con Haesbaert (2013: 20) en advertir que resulta usual identificar investigaciones en las que el espacio aparece como "un palco" y no como constitutivo de las relaciones sociales, las cuales no podrían tener lugar sin la construcción de ese espacio. Agregamos, esta percepción incluso puede extenderse a las políticas públicas de aspiración regional. Cualquier intervención que se precie de tal, debería asumir que:

[...] el capitalismo ya no se apoya solamente sobre las empresas y el mercado, sino también sobre el espacio [...] Es, pues, el espacio entero lo que se ha definido como algo dominante y dominado [...] el espacio ha sido siempre político pero ahora 
lo es más que nunca. En el espacio planetario [...] se enfrentan las estrategias y en lo concerniente a la estrategia todo es un asunto de espacio" (Lefebvre, 1974: 221).

Entendemos que en una visión relacional del espacio, éste es constituyente. Además de resultar significativos los objetos (por ej., una empresa privada, una cooperativa, una explotación agropecuaria, etc.) que se interponen/interrelacionan, importan las relaciones insertas adentro del propio objeto. De tal modo, el objeto se define por la relación que construye a través de y con el espacio. En definitiva, la relación también constituye el objeto (Haesbaert, 2013: 20).

Desde la perspectiva dialéctica que aquí suscribimos, las distribuciones espaciales y las diferenciaciones geográficas pueden ser el resultado de los procesos sociales, aunque también condicionan el funcionamiento de tales procesos (incluso el de los fenómenos naturales, aun considerando la frontera espacial y temporalmente difusa de nuestra percepción sobre lo "social" y lo "natural"). Entonces, "lo espacial" es más que un resultado, es parte de la explicación. Aunque no son la forma espacial, la distancia y/o el movimiento los que de por sí solos poseen efectos, sino la forma espacial que adoptan los procesos sociales particulares y específicos en cada lugar, así como las relaciones sociales que en él se desarrollan. En suma, a nuestro juicio una definición completa de lo espacial debería incluir un registro de procesos sociales, la distancia - así como su impronta y connotación en cada tiempo y sociedad-, los movimientos, las diferenciaciones entre lugares, sus simbolismos e identidades (Massey, 2012: 103).

Además del citado registro, al aludir a la palabra "proceso", intentamos dotar al espacio de temporalidad. Desde nuestra visión, esto resulta vital para discutir el rol de las burocracias en la usual desestimación y/o subestimación de las contradicciones inherentes al espacio. Cuando señala que los tecnócratas "no creen en las contradicciones del espacio", Lefebvre (1974: 226-227) advierte varias cuestiones. En sintonía con el autor, entendemos que el uso de la palabra "creencia" resulta clarificador para exponer que las políticas de desarrollo pueden partir de ideas preconcebidas que orientan las intervenciones en el espacio. Éste tendió a concebirse como una dimensión dependiente del tiempo (usualmente cronológico, el ligado a la circulación del capital, a la organización del trabajo). Sin embargo, según Lefebvre (1974), el espacio se torna dimensión central para el capital, dado que éste organiza el tiempo a su favor (momentos de ocio, ritmos de trabajo, carreras académicas, organización familiar, etc.), aunque no ha podido abstraerse de las contradicciones que en el espacio se suceden y a través del mismo operan (distancias, movimientos, barreras, identidades, escalas, burocracias de diversos órdenes de gobierno, etc.). En esta dirección, puede entenderse que el capital pretenda modificar "la escala a la que opera de tal forma que sitúa los poderes [estatales] y su influencia [en] la escala que le resulta más ventajosa para la reproducción de su propio poder" (Harvey, 2014: 147). 
Esas contradicciones a las que alude Lefebvre (1974) se ligan con el hecho de que el espacio contiene objetos heredados del pasado. Usualmente, éstos han tenido una génesis ligada a otros propósitos y perduran debido a que pudieron ser adaptados a nuevas necesidades ${ }^{4}$. Las formas espaciales heredadas del pasado y presentes en la organización actual expresan una funcionalidad efectiva en términos económicos o un valor simbólico que justifica $-\mathrm{O}$ no- su permanencia (Lobato Correa, 2000: 38).

Las herencias resultan relevantes a la hora de diseñar una intervención en materia de política pública. Esta cuestión es central para Lefebvre (1974: 221-222) cuando plantea que por tratarse de algo complejo el capitalismo no ha logrado una planificación espacial que tienda a una mejora en las condiciones de vida de los grupos vulnerables. Según Lefebvre (1974), esto sucede por varios motivos. En primer lugar, el crecimiento económico más inmediato se realiza sobre nodos centrales (ciudades y/o regiones cuyas "rugosidades" ofrecen una rápida valorización del capital) aunque ello conduzca a su vez a la generación y al incremento de las brechas sociales en relación a los nodos periféricos. En segundo término, el autor considera que es en el espacio y por el espacio donde se genera la reproducción de las relaciones de producción capitalista. Esto implica que el mismo se conciba como un espacio instrumental, un ámbito donde las burocracias y el discurso tecnocrático inciden para transformar el espacio social en espacio abstracto (cuantitativo, geométrico, matemático, catastral). En tercer lugar, Lefebvre encuentra que la principal contradicción en la que incurren las burocracias vinculadas a la planificación radica en una cuestión de escalas: intentan conocer para transformar el espacio a escala planetaria, aunque éste se encuentre fragmentado por el régimen de propiedad privada y se halle supeditado a las estrategias de mercado (1974: 223224). La situación resulta aún más compleja si se considera que las múltiples estrategias de diversas burocracias públicas y privadas que intervienen en las distintas escalas se entremezclan, se superponen, se integran, entran en contradicción y competencia.

Los aspectos citados en torno a la noción de espacio resultan centrales para comprender las estructuras, los funcionamientos, la reproducción y transformación de las sociedades en sus partes o en su totalidad, así como para acercar el diseño de cualquier intervención pública a sus consecuencias efectivas. Diseño que, como observaremos a continuación, también debería tomar nota del Poder y, sobre todo, del poder.

\footnotetext{
${ }^{4}$ Milton Santos (1978, citado en Lobato Correa, 2000: 39) denomina "rugosidades" a estas formas espaciales. Se trata de una alocución de la geomorfología que designa las marcas del pasado en el espacio, aunque esa presencia acaba condicionando la cotidianeidad. Si se proyecta este razonamiento en el tiempo, puede considerarse que las formas espaciales tienen implicancias sobre el futuro de la sociedad (Lobato Correa, 2000).
} 


\section{Poder}

La noción de poder es quizás una de las de aprehensión más escurridiza para las ciencias sociales. Su laxitud obedece a diversas cuestiones, entre ellas al hecho de que se trata de una noción relacional, que puede modificar sus contenidos dependiendo del concepto con el que se la asocie. Raffestin (1993: 5) es consciente de esto cuando entiende que al consistir en actos, en decisiones, el poder se representa de manera difusa. Asimismo, esta relativa imprecisión se liga con su compleja operacionalización y con el hecho de que sigue siendo asociado unívocamente al accionar estatal. Ello no obsta para intentar de forma iterativa aproximarnos a definiciones que permitan dotar de significados más precisos a la noción.

Haesbaert (2013: 25) considera que si adoptamos una versión tradicional de la noción, la referida al Poder del Estado o al poder de la clase hegemónica, el territorio ${ }^{5}$ aparece como un macro-territorio usualmente ligado a las estructuras políticoeconómicas dominantes (provincias, regiones, asociaciones estatales). En cambio, si se aborda al poder también como un movimiento de resistencia que se encuentra involucrado en diversas relaciones sociales, podrán observarse micro-espacios y habrá formas alternativas de concebirlos. Estos aspectos han motivado a Foucault (pfr. 1980) a considerar que podría escribirse toda una historia de los espacios - que a la vez constituiría una historia de los poderes-, desde las más significativas estrategias de la geopolítica hasta las micro-tácticas del hábitat, de la arquitectura institucional, del aula o de la organización hospitalaria, pasando por las implantaciones económico-políticas.

A principios de siglo XXI, las diversas y simultáneas resistencias a la vigencia de la interpretación neoclásica de la economía se pueden considerar como confrontaciones por el espacio. Desafían la tendencia del capitalismo contemporáneo hacia la producción del "espacio abstracto", donde el pensamiento económico hegemónico - sirviéndose de la tecnocracia - ha influido decididamente en la mercantilización de la vida social (Oslender, 2010: 97). Revisitando a Lefebvre, aquel autor considera estas disputas como la "búsqueda de un contra-espacio" (Oslender, 2010).

En un sentido relacional, el poder no podría apreciarse en tanto capacidad $\mathrm{u}$ objeto. Desde este enfoque, se trata de relaciones de fuerza desiguales que se reproducen mediante prácticas. Por lo tanto, más que definir el poder o construir una teoría

\footnotetext{
5 "El concepto de territorio lleva implícitas las nociones de apropiación, ejercicio de dominio y control de una porción de superficie terrestre, pero también contiene las ideas de pertenencia y de proyectos que una sociedad desarrolla en un espacio dado [...] La apropiación y transformación de un espacio por parte de una sociedad implica entonces la construcción de un territorio, su uso, su conversión en un "territorio usado" (Santos y Silveira, 2004). El territorio puede entenderse así como la manifestación concreta, empírica, histórica, de todas las consideraciones que en un plano conceptual se hacen en torno al espacio" (Blanco, 2007: 41-43). Por tratarse de un artículo con carácter teórico, aquí empleamos la noción de espacio.
} 
del poder, resulta necesario analizar las prácticas del poder, cómo el poder se desarrolla concretamente produciendo espacio (Haesbaert, 2013: 25-26), cómo estas se desenvuelven en los intersticios de las políticas de desarrollo, pudiendo vaciar sus contenidos, dificultando su ejecución o transformando a sus destinatarios y usufructuarios efectivos.

La noción de poder como relación resulta útil para los análisis en torno a los sujetos sociales, sus prácticas y sus vinculaciones con las políticas de desarrollo. Sin embargo, al referirnos a esta perspectiva estamos aun omitiendo un análisis sobre el porqué de la ligazón entre Poder y Estado, así como la aparición indisolublemente asociada (y naturalizada) de ambas nociones.

El trabajo en cierta medida fundacional de Raffestin resulta útil para abordar la imbricada vinculación entre Poder y Estado. Este autor (1993: 5) considera que a partir del momento en que el Estado resulta equivalente a lo político, la categoría de Poder Estatal se ha instituido como única, unívoca $-\mathrm{y}$ hasta monolítica en análisis binariamente simplistas-. De este modo, diversos estudios que abordan los conflictos en clave ratzeliana ${ }^{6}$ consideran a éstos como enfrentamientos geopolíticos entre Estados. Raffestin (1993: 14) va a discutir los enfoques unidimensionales que desde la Geografía colocan en el centro del análisis al Estado y/o desconocen que toda relación es punto de origen $-\mathrm{y}$ distribución - del poder, cuestión que fundamenta la multi-dimensionalidad del mismo. Para aquellos enfoques unidimensionales, que incluso abonaban hasta fines de siglo XX el fin de la historia y la negación de la política, el Estado detenta el Poder y es el único que lo detenta. En el mejor de los casos, se lo asociaba con un poder superior, por lo que resulta necesario abordar los poderes inferiores que podrían interactuar con él (Raffestin, 1993: 5).

Coincidimos con Haesbaert (2013: 25-26) en considerar al poder más allá de la intervención estatal, simbolizado en un conjunto de prácticas materiales como la coacción y el control. Precisarlo de ese modo sería acotar su alcance, puesto que el poder detenta también un carácter simbólico, manifiesto en aspectos tales como la construcción de agendas, de consensos. Estos últimos pueden pensarse como la determinación de la voluntad de quienes usufructúan una relación en su beneficio para ordenar escenarios y dirigir a los sujetos sociales en función de objetivos que nunca suelen expresarse de forma directa, sino más bien a través de prácticas educativas y trayectorias institucionales cristalizadas en visiones naturalizadas, hasta culturalmente colonizadas.

Por lo dicho, consideramos que tal como acontece con las nociones de espacio y desarrollo, la de poder se encuentra inmersa en un área de ambigüedades, posiblemente mayores que las dos primeras. Entre otras cuestiones, Raffestin (pfr. 1993: 13)

\footnotetext{
${ }^{6}$ Desde una perspectiva ratzeliana, los análisis territoriales se enfocaban en el Estado, desconociendo o bien subestimando otras organizaciones dotadas de poder político.
} 
encuentra que su imprecisión radica en que la palabra puede ser escrita con mayúscula o con minúscula. Iniciada con mayúscula, implica la historia de nuestra equiparación a un conjunto de instituciones y de aparatos que garantizan la sujeción de los ciudadanos a un Estado determinado, al control que este ejerce sobre un territorio que constituye continuamente con su intervención y a los ciudadanos que lo integran. En sus aspectos esenciales, el Poder postula la soberanía del Estado, las características que adquiere la legislación, se trata de formas "terminales". Según Raffestin (1993: 13) esta afirmación resulta de significativo valor, puesto que expresa una concepción unidimensional del poder que prácticamente oculta una perspectiva comparativamente más compleja y enriquecedora para nuestro enfoque.

Desde nuestra perspectiva, el análisis de Claval (1982: 23 y ss.) en torno a la noción de poder en el espacio resulta relevante para discutir la concepción unidimensional a la que aludimos arriba. Este autor considera que la dimensión del poder en el espacio fue relegada de los análisis económicos referidos a fenómenos de dominación. Por poder, Claval entiende tanto la capacidad de actuar como la de lograr que otro actúe. En esta última acepción, el poder se manifestaría en las relaciones, mediante asimetrías. Para el autor, la dificultad de abordar fenómenos de poder radicaría en su multiplicidad de formas: para llegar a idénticos resultados, las sociedades reproducen tipos diversos de relación, lo cual explicaría las variadas dimensiones y complejidades de la organización espacial. En tal sentido, Claval (1982) emplea la distinción weberiana entre poder coercitivo - surgido del uso de la fuerza- y poder legítimo - emanado de la delegación de atribuciones sociales al Estado- para identificar sus implicancias en el espacio (Claval, 1982: 53) y destacar la relevancia de éste en el mantenimiento de estructuras jerárquicas.

Lejos de desestimarse, el Poder se torna más familiar, decisivo y habitual cuando aparece como nombre propio. Esto resulta posible en tanto se reproduce - no casualmente- la confusión entre Estado y Poder. Sin embargo, seguir pretendiendo que el Poder solo es el Estado implicaría esconder el poder con minúscula, ese que ya en la década de 1970 era conocido con la etiqueta de "poderes fácticos". Raffestin (pfr. 1993: 13) considera que el poder nació cerca del Poder, junto con la historia que contribuyó a construir. El poder, nombre común, se esconde detrás del Poder, nombre propio. Paradojalmente, se oculta más efectivamente cuanto mayor resulta su presencia. El poder como relación se encuentra presente aunque oculto, con su tendencia a quedar disfrazado, incluso a negarse como poder (de Souza Silva, 2009: 3), a tomar el ropaje del oprimido. Presente en cada relación, en la dinámica de cada acción. La ambigüedad que comprende a la noción resulta advertible allí, donde se encuentran el Poder con el poder. El primero resulta relativamente más identificable, reconocible, debido a que se manifiesta por intermedio de las instituciones y tecnologías que circunscriben el territorio del Estado, controlan la población y dominan los recursos (materiales y simbólicos) mediante las políticas públicas. En tanto tal, el Poder aparece como peligroso para quienes consideran la intervención del Estado dirigida a controlar, disciplinar, vigilar y castigar. De tal 
modo, el Poder inspira la desconfianza por la propia amenaza que representa, la cual resulta advertible. Sin embargo, el más inquietante es aquel que no se percibe, el que no necesariamente se encuentra instituido en una organización social como el Estado, nos referimos al poder (pfr. Raffestin, 1993: 13-14).

Hemos llegado a diferenciar el poder respecto del Poder. Sin embargo, aún resta terminar de definirlo. Siguiendo a Foucault (1986: 104) y a Raffestin (1993: 14), puede precisarse que el poder se expresa por ocasión de una relación. Por ende, se trata de un proceso de intercambio en el que se complementan o confrontan -al menos- dos polos (personas, grupos, etc.). Las fuerzas de las que disponen los polos conllevan a la creación de un campo, un campo de poder. No se trata de una institución ni de una estructura, sino de la nominación de una situación social compleja que se desenvuelve en un tiempo y espacio determinado. Consiste en procesos que exceden al control y la represión. Posiblemente, este es un aspecto de lo paradójico de su eficacia, no poder nada, solo lograr que nada se pueda, excepto lo que deja hacer (pfr. Foucault, 1986: 104). Esta paradoja suele materializarse mediante la coacción, la imposición o la amenaza. Para que la amenaza funcione, se requieren ciertas circunstancias, así como un campo de poder a través del cual se puedan materializar sus efectos performativos (Butler, 1997: 31).

Al considerar al poder como un proceso relacional, no circunscripto únicamente al poder punitivo mediante el cual la clase capitalista reprime desde su control del Estado las reivindicaciones de la clase trabajadora (Fair, 2010: 15-16), Foucault (2003) intenta desenmascarar las particularidades del poder: i) no se adquiere, es ejercido a partir de innumerables polos; ii) surge desde abajo, no puede identificarse una oposición binaria y global entre opresor y oprimido; iii) implica resistencia y, por lo tanto, esta no se produce en una posición ajena al poder. Las formas de resistencia pueden entenderse no como opuestas al poder, sino como constituyentes de las relaciones de poder (Haesbaert, 2013: 26). En cuanto a estas, Foucault (2003) señala que: i) no son independientes a otros tipos de vinculaciones (económicas, sociales, tecnológicas) aunque son inmanentes a ellas; ii) resultan intencionales y objetivas. Toda relación implica poder, eso significa que éste se liga con la manipulación de los flujos que atraviesan, posibilitan, complejizan y/o desactivan una relación, se trata de energía e información (Raffestin, 1993: 15).

El lazo entre el poder y el saber resulta evidente, aunque no puede concebirse a través de información o energía en estado puro, sino de una combinación de ambas. El poder también establece qué saber es legítimo, algo que resulta habitual en las políticas de desarrollo. De acuerdo a Silveira (2006: 71), la producción de un discurso que encubre una elección corporativa como si fuera el mentado e incierto "interés general", busca orientar la conciencia social para fragmentar el espacio, para privatizarlo en aras de la modernización. Esta es quizás una de las paradojas del desarrollo, tal como aquí lo expondremos. Para que esto suceda, las políticas públicas deben imaginarse, legitimarse y actuar desde una visión modernizadora. No obstante, esta perspectiva es una entre varias, puesto que el conjunto de posibi- 
lidades del período resulta aún mayor que el de las opciones que figuran en la agenda pública. La misma elección por estrategias amparadas en cosmovisiones sedimentadas y caminos recorridos parece suficiente para evidenciar que los sujetos sociales que comandan la producción y el uso del espacio resultan particularmente productores de límites, de una racionalidad que se vuelve irracionalidad para las mayorías (pfr. Silveira, 2006: 71), en una pérdida de derechos civiles y/o su retracción - tal como se observa en la legislación laboral de países sometidos a procesos de endeudamiento externo-.

Hasta el momento hemos discutido el Poder asociado al Estado. Hemos llegado a una reflexión preliminar, el poder es relacional, se desenvuelve a partir de la formación, acumulación, combinación y circulación de energía e información. Restaría agregar que esta noción posee dimensiones temporales y espaciales. Para ello, podemos remitirnos a Santos (pfr. 1996, citado en Silveira, 2006: 65), quien considera al tiempo como período y, agregaríamos, en tanto hito. Pues, desde nuestro enfoque lo relevante serían los sucesos significativos para los sujetos sociales, no tan solo el transcurrir del cronómetro. Es decir, no como tiempo cronológico y abstracto, sino como un conjunto de posibilidades efectivas de dichos sujetos, quienes no disponen de igual capacidad para satisfacer/imponer sus necesidades y acceder a ciertas posibilidades. Santos estima que la forma en que esas posibilidades resultan aprehendidas son múltiples: división social del trabajo, división territorial del trabajo, topologías, circuitos espaciales de producción y acumulación, círculos de cooperación, entre otras categorías. Cuando esas posibilidades se vuelven efectivas por medio de la desigual capacidad de imposición de los sujetos sociales en sus relaciones cotidianas, estaríamos frente al pasaje de la sociedad — que es el ser- al espacio — que es el existir- (Santos, 1996, citado en Silveira, 2006: 65). Esa es una de las expresiones del papel activo del espacio (Santos, 1996, y M. Santos et al., 2000, citados en Silveira, 2006: 65) y de la relevancia del poder en la constitución del mismo.

En esta instancia, al concebir al poder más allá del Estado y entenderlo como noción relacional, podremos arribar a una concepción multi-escalar del espacio. Esto lleva a interrogarnos sobre la vinculación entre espacio y poder en las políticas desarrollo.

\section{Desarrollo}

En 1949, el Presidente estadounidense Harry S. Truman no fue original al enunciar el término "desarrollo" en el discurso a su nación, construido por años y años precedentes de preocupaciones y percepciones. En efecto, Esteva (2000: 70-72) encuentra evidencias para sostener que casi dos siglos antes este término era empleado en diferentes contextos. Esta noción se fue edificando en torno a la idea de 
meta, camino teleológico, en el que se debería alcanzar un estado de cosas deseables, al que resulta esperable llegar (Isla y Colmegna, 2005).

El citado discurso de Truman en 1949, así como una política exterior norteamericana dirigida a consolidar su hegemonía cultural y económica han sido aspectos significativos para que la noción de desarrollo permaneciera en la agenda pública. En ese sendero puede situarse la "Alianza para el Progreso" - 1961/1970—, la "Guerra contra el hambre" - 1962 - fomentada desde la UNESCO, así como la "Revolución verde"7 — vigente entre 1940-1970 y difundida desde la USAID—, entre variadas iniciativas.

Un rasgo común a la diversidad de iniciativas consiste en que la acumulada adjetivación relativa al desarrollo (social, económico, territorial, rural, integrado, local, humano, sostenible, sustentable y un largo etcétera) responde a la capacidad de distintas escuelas y burocracias para interpelar, resaltar e imponer aspectos sociales que alternativamente se han puesto en debate. Sin embargo, esta proliferación también expondría la ineficacia manifiesta de las intervenciones realizadas bajo el espíritu del desarrollo para transformar las condiciones materiales de las poblaciones sobre las que se pretende intervenir (Ribeiro, 2007: 179; Rist, 2002: 5; Escobar, 2005: 18; Comeliau, 1997: 30).

En lo que respecta a nuestro objetivo, cabe exponer tres aspectos que suelen encontrarse incluidos implícitamente en los postulados de políticas públicas que recurren a la noción de desarrollo para, en el siguiente apartado, concluir con un análisis de las burocracias.

En primer término, cabe considerar que el desarrollo como noción se asume desde una presunta objetividad. De tal modo, aparece naturalizada la clasificación entre unidades político-administrativas - que se asocian linealmente con sociedades-. Esta naturalización opera a la hora de diseñar y ejecutar una intervención pública debido a que direcciona un modo de operar en el espacio, moldea una forma de evaluar las dinámicas productivas y acota previsiblemente el horizonte de lo posible y lo probable. Resulta habitual encontrarnos con diversidad de indicadores, neutros y a-valorativos solo en apariencia: producto bruto interno y/o geográfico y/o per cápita, índice de desarrollo humano, etc. Aquí no se discute la rigurosidad metodológica con la que se pueden construir estos y otros indicadores, los cuales son sometidos a diversidad de debates, ensayos y métodos de recolección. En cambio, se plantea la necesidad de un debate previo acerca de las cosmovisiones

\footnotetext{
${ }^{7}$ El término fue acuñado en 1968 por el entonces Director de la USAID William Gaud, quien destacó la difusión de las nuevas tecnologías (variedades de cereales asociadas a agroquímicos). En su discurso en la Sociedad para el Desarrollo Internacional, señaló que: "estos y otros desarrollos en el campo de la agricultura contienen los ingredientes de una nueva revolución. No es una violenta revolución roja como la de los soviéticos, ni es una revolución blanca como la del Sha de Irán. Yo la llamo la «revolución verde»" (SID, 1968).
} 
que luego se hacen operativas en la construcción de los indicadores ${ }^{8}$. Éstos avalan técnicamente y legitiman socialmente la confección de rankings que establecen diferenciaciones - traducidas implícitamente como discriminación- (D. Slater, 2000: 139). Pueden justificar un status quo, una forma de evaluar las dinámicas sociales y las políticas públicas. En el plano de la intervención, las cosmovisiones inciden decididamente, puesto que el devenir de diversos programas depende de las prácticas políticas de los actores, que pueden ser o no conscientes de las etapas de un proyecto o bien del andamiaje conceptual que incide en la operacionalización de indicadores y actividades. Por lo tanto, la perspectiva conceptual desde la cual se aborda un proyecto debería ser clara para los sujetos sociales involucrados (Isla y Colmegna, 2005: 10).

En segundo lugar, resulta advertible que el uso habitual de la noción de desarrollo suele transformar el espacio en tiempo (Massey, 2012). Este aspecto se logra de diversas formas. Al menos desde el momento en que el desarrollo se transformó en un leitmotiv para la política exterior estadounidense - asociada a las políticas comerciales de las principales corporaciones-, puede entenderse la vocación espacial que ha tenido la noción (D. Slater, 2000: 139-140). Nótese que se trata de una alocución que apela a metáforas temporales sostenidas en visiones evolucionistas, que describen al tiempo en términos cronológicos y lineales: rezagados, en vías de desarrollo, el tren del progreso, etc. Una noción que clausura la posibilidad de pensar múltiples tiempos y espacios no sometidos a una lógica totalizadora en la que las reglas de juego son puestas por quienes evalúan desempeños, en base a indicadores pretendidamente a-sépticos que construyen un imaginario de cantidades más que de calidades, particularidades y cualidades.

En tercer término, ligado con la problemática de las cosmovisiones que sustenta el desarrollo, esta noción suele nutrirse desde perspectivas dicotómicas que tienden a presentarse como a-valorativas y/o asépticas. Usualmente afirmada en las teorías de la modernización, la noción de desarrollo se construye a partir de dicotomías que serían útiles para describir un escenario de intervención aunque carecen de precisión para caracterizar situaciones que no pueden catalogarse como opuestas o contradictorias. Esta estrategia metodológica dirigida a presentar escenarios simplificados como binarios recorre diversas perspectivas de pensamiento. Entre las teorías de la modernización cabe destacar a las etapas de crecimiento, obra publica-

\footnotetext{
${ }^{8}$ En tal sentido, puede comprenderse que: "la estructuración de la sociedad no está ligada, primordialmente, a la distribución de los recursos, al estatus reconocido a unos y otros, a la riqueza adquirida y al poder ejercido por algunos. Resulta de la influencia que ejercen aquellos que crean las categorías utilizadas para aprehender lo real y crean palabras para traducirlas: cada uno recibe, de este modo, de las personas que frecuenta, filtros que le hacen percibir lo real bajo una perspectiva específica. Conoce el mundo y el universo social a través de los discursos que le dan a ver, los jerarquizan e interpretan" (Greimas y Courtes, 1979, citado en Claval, 2002: 35).
} 
da por Rostow en 1947, que por su difusión adquirió un status especial entre las perspectivas neoclásicas en torno al desarrollo?

Escobar (2005: 17) considera que desde una perspectiva neoclásica, la teoría de la modernización ha implicado para académicos y elites mundiales un período de certezas a partir del supuesto que el capital, la ciencia y la tecnología poseen implicancias beneficiosas sobre los grupos vulnerables en los que las políticas públicas pretenden intervenir. No obstante, esta certidumbre ha sido cuestionada por las teorías de la dependencia - en cuyo seno pueden identificarse marcos conceptuales marxistas, keynesianos y más recientemente regulacionistas-, desde las que se discute una supuesta carencia de capital, tecnología o valores modernos como causales de las desigualdades sociales. En cambio, proponen que el "sub-desarrollo" posee su fuente en la conexión entre dependencia externa y explotación interna, la causa del problema se encuentra en la propia dinámica del capitalismo. Aún a pesar de los enfoques disímiles, los planteos de la modernización y de la dependencia han demostrado una efectividad incierta a la hora de ejecutar las intervenciones y exponer resultados, debido a su inaplicabilidad (y replicabilidad), por el desinterés de los "beneficiarios" y/o por modificar negativamente sus condiciones de vida (por caso, vía desposesión material y/o colonización cultural).

La crítica a la noción de desarrollo también puede advertirse desde lo que Fernández et al. (2007) han denominado "nueva ortodoxia regionalista", con auge en la década de 1990 a partir de precedentes de décadas anteriores. Las fuentes de la misma se ubican tanto en el estudio de las transformaciones del régimen de acumulación acaecido desde finales de la década de 1960 como en las propuestas conceptuales realizadas desde diversas vertientes. En este aspecto, los autores (2007: 64) citan las nociones de "distritos industriales", "medios innovadores", "regiones aprendientes" y clusters (Becattini, 1992; Brusco, 1982; Crevoisier, 2005; Asheim, 1995, y Porter, 1990, citados en Fernández et al., 2007: 64), a los que puede agregarse el "desarrollo territorial". Estos enfoques han introducido una dimensión espacial y un enfoque que considera la multi-escalaridad (arriba-abajo), apelando asimismo al potencial de la cooperación. Los mismos mostraron distancias del discurso de desarrollo con el que las ideas neoclásicas habían influido en las políticas públicas en la Argentina de finales de siglo XX. Sin embargo, los neologismos

\footnotetext{
${ }^{9}$ Las etapas del crecimiento económico. Un manifiesto no comunista fue escrito por Rostow (1961) mientras ocupaba cargos como el de Presidente del Consejo de Planificación Política de Estados Unidos y el de Embajador ante la Alianza para el Progreso. Se trataba de una teoría desplegada en cinco etapas/estadios (tradicional, condiciones previas al impulso inicial, impulso inicial [take off], marcha hacia la madurez, era del gran consumo de masas). Esta obra sufrió diversas críticas: el carácter cuantitativo con el que se caracterizan sociedades; la universalidad del proceso mediante el cual se produciría el tránsito de menos a más; la presencia de una secuencia lineal para el desarrollo de etapas o momentos sucesivos empíricamente reconocibles y una teoría evolutiva lineal, que emplea un método comparativo con el que se generaliza a partir de casos puntuales, simplificando las respuestas ante problemas disímiles (F. Slater, 1999: 120-121).
} 
no siempre albergan ideas nuevas o bien son empleados con significados que pretenden discutir (por caso, proponer un programa de competitividad para agricultores familiares o los micro-emprendimientos sin agregado de valor).

Por último, a partir de las décadas de 1980 y 1990, los magros resultados en la intervención han sido expuestos por los enfoques postestructuralistas. Estas perspectivas cuestionan el concepto mismo de desarrollo, entendiéndolo como un discurso de origen occidental que opera como mecanismo para la producción cultural, social y económica del denominado Tercer Mundo (Ferguson, 1990; ApffelMarglin y Marglin, 1990; Escobar, 1996, y Rist, 1997; citados en Escobar, 2005: 17). Al partir de premisas inconsistentes, se está ante propuestas inadecuadas (de Souza Silva, 2009: 1) para la resolución de problemas que la política pública pretende atender. Esas premisas pueden partir del valor que socialmente se le concede al saber experto, desconociéndose las carencias de formación y los prejuicios (sean étnicos, etarios, religiosos, de clase, etc.) con los que los denominados agentes de desarrollo pueden intervenir. En cambio, desde los enfoques postestructuralistas se propone que las sociedades: i) decidan su sendero político-económico sin condicionamientos de organismos multilaterales de crédito, ii) adquieran deuda solo en caso de poseer garantías de devolución, iii) exploten ventajas comparativas de sus economías en beneficio de los sectores vulnerables, iv) evalúen la factibilidad y conveniencia de acuerdos comerciales, v) incidan vía regulación en la estabilización de precios de materias primas, vi) generen tecnologías autóctonas como medio para reducir la dependencia de las multinacionales y vii) hagan énfasis en sus posibilidades más que en sus carencias (Rist, 2002).

\section{Políticas de desarrollo: alcances y limitaciones}

Los tres aspectos antes expuestos sobre desarrollo —noción que se asume desde una presunta objetividad, que suele transformar el espacio en tiempo y accionar a partir de perspectivas dicotómicas supuestamente a-valorativas y/o asépticascuentan con potencial para brindar herramientas a través de las cuales interpelar a las intervenciones estatales. A continuación realizamos un breve ejercicio analítico, que - sin pretender exhaustividad- expone elementos para indagaciones futuras. En función de la extensión de esta contribución, presentaremos dos $\operatorname{casos}^{10} \mathrm{de}$ análisis: el Programa de Atención a Grupos Vulnerables (PAGV) y el Programa Nacional de Microcrédito para la Economía Social (PMES). Si bien el último

\footnotetext{
${ }^{10}$ La selección de los dos casos resulta de una búsqueda y sistematización de experiencias de intervenciones estatales en materia de desarrollo para el caso argentino. Esta elección se realizó en función de un análisis de los tres roles que cumplen las burocracias y los tres aspectos reseñados sobre la noción de desarrollo, así como los referidos a las nociones de espacio y poder.
} 
precede al primero cronológicamente, ello no obsta a que puedan identificarse políticas de desarrollo que combinen aspectos de ambos o en las que perduren lineamientos clásicos que observaremos en el caso del PAGV.

La producción de límites antes citada (Silveira, 2006: 71) originalmente se encuentra enfocada en los sujetos sociales que comandan la producción y el uso del espacio, sobre todo en las grandes empresas. Aquí interesa señalar la producción de límites y/o su corrimiento desde las burocracias estatales en la ejecución de políticas de desarrollo dirigidas a grupos vulnerables.

A efectos expositivos, los dos casos de intervenciones a tratar se resumen conceptualmente en el Cuadro 1.

Cuadro 1. Burocracias y tipos de políticas de desarrollo: PAGV y PMES

\begin{tabular}{|c|c|c|c|}
\hline \multirow[b]{2}{*}{ Rol de la burocracia } & \multirow{2}{*}{$\begin{array}{c}\text { Objetivo de } \\
\text { la intervención }\end{array}$} & \multicolumn{2}{|c|}{ Tipo de políticas de desarrollo } \\
\hline & & Asistencialistas (PAGV) & $\begin{array}{c}\text { Postestructuralistas } \\
\text { (PMES) }\end{array}$ \\
\hline Sectorial & $\begin{array}{l}\text { Asumir representación } \\
\text { de intereses de la propia } \\
\text { burocracia }\end{array}$ & $\begin{array}{l}\text { Sujeto de intervención } \\
\text { pasivo definido por } \\
\text { tecnocracias, como } \\
\text { ajeno al Estado }\end{array}$ & $\begin{array}{l}\text { Sujeto de intervención, } \\
\text { de derecho, que integra } \\
\text { la función pública y se } \\
\text { codefine con organiza- } \\
\text { ciones. }\end{array}$ \\
\hline Mediador & $\begin{array}{l}\text { Garantizar los intereses } \\
\text { de los sectores econó- } \\
\text { micamente dominantes. }\end{array}$ & $\begin{array}{l}\text { Contención de conflic- } \\
\text { tos sociales derivados } \\
\text { de ajustes estructurales } \\
\text { vía capacitación para la } \\
\text { auto-explotación; } \\
\text { aprovechamiento de } \\
\text { ventajas comparativas } \\
\text { (por ej., exportación de } \\
\text { granos) }\end{array}$ & $\begin{array}{l}\text { Resolución de conflic- } \\
\text { tos sociales a partir de la } \\
\text { inclusión de demandas } \\
\text { sociales en una nueva } \\
\text { agenda de políticas de } \\
\text { desarrollo. }\end{array}$ \\
\hline Infraestructural & $\begin{array}{l}\text { Perseguir el cumpli- } \\
\text { miento de los objetivos } \\
\text { que responden al interés } \\
\text { general }\end{array}$ & $\begin{array}{l}\text { Interés general ligado a } \\
\text { asuntos éticos (por ej., } \\
\text { combate a la corrup- } \\
\text { ción) más que políticos } \\
\text { (por ej., redistribución } \\
\text { de la riqueza }\end{array}$ & $\begin{array}{l}\text { Interés general ligado a } \\
\text { generar inclusión social } \\
\text { a partir de empleo y } \\
\text { fomento a formas de } \\
\text { organización alternativa }\end{array}$ \\
\hline
\end{tabular}

Fuente: Elaboración propia.

El PAGV fue inicialmente financiado por el Banco Interamericano de Desarrollo (BID) y ejecutado por la entonces Secretaría de Desarrollo Social de la Nación en 1996/97. Según evalúa un informe del Centro de Estudios Legales y Sociales (CELS) (2007), se trató de un programa focalizado en grupos vulnerables que no recibieran subsidios estatales y residieran en áreas urbanas: jóvenes, mujeres jefas 
de hogar, adultos mayores, discapacitados y población indígena. En 2002, el PAGV agregó el componente de transferencia de ingresos, incorporándose entre 2005 y 2011 al Plan Familias y sucedáneos ${ }^{11}$. Los objetivos explícitos del programa fueron reducir la exposición de grupos de alta vulnerabilidad a riesgos sociales y económicos, intentando mejorar su calidad de vida, así como la eficiencia y eficacia de la inversión social. Para ello, contaba con cuatro componentes: i) transferencia de ingreso; ii) accesibilidad a servicios sociales; iii) fortalecimiento institucional; y iv) atención a la población indígena. El programa buscaba promover la participación de las mujeres en actividades de desarrollo personal, familiar y comunitario y requería como contraprestación controles de salud periódicos y la asistencia a la escuela de los hijos (CELS, 2007: 16-17).

Colmegna (2005: 131-138) sostiene que programas como el señalado, se han fundamentado en una noción teleológica de desarrollo. Esta perspectiva sugiere que los sectores vulnerables encontrarán una forma rápida de integrarse como miembros plenos de derecho en la sociedad. Habitualmente, los programas de asistencia a la pobreza ejecutados hasta principios de siglo XXI en Argentina han propendido a la reproducción de estrategias ligadas a la capacitación para la auto-explotación, el auto-consumo y la auto-producción (Alemany, 2008: 31). Asimismo, han planteado estrategias participativas en las cuales la toma de decisiones nodales resulta ajena a los sujetos de la intervención y se encuentra centralizada a nivel de las burocracias (Colmegna, 2005: 131-138).

En esta dirección, estudios como el realizado por Ferguson (1994) para el caso de Lesotho, poseen el valor de evidenciar que las burocracias del llo - conformadas por organismos de crédito, agencias estatales y organismos no gubernamentales - podrían actuar como mecanismos para mantener y reforzar el ejercicio de su poder, asumiendo la pobreza como una dimensión de justificación para su propia acción sostenida desde las diversas y cambiantes modas conceptuales (marginalidad, exclusión, vulnerabilidad, etc.). Una intervención en esa línea, circunscribe los significados de la participación de los grupos vulnerables, reduciendo su condición material a problema de resolución meramente tecnocrática. En esta se naturaliza la desmovilización y la despolitización mediante respuestas focalizadas espacio-temporalmente y particularistas, que reducen la causa de lo que el

\footnotetext{
${ }^{11}$ Hasta noviembre de 2009, momento de la implementación de la Asignación Universal por Hijo (AUH), el Plan Familias (Ministerio de Desarrollo Social de la Nación) y el Plan Jefas y Jefes de Hogar eran los dos principales planes de cobertura social. Dado que los mismos son incompatibles con el cobro de la AUH, se realizó un traspaso de sus beneficiarios al régimen de $\mathrm{AUH}$, de modo tal que los mismos dejaron de cobrar los planes para pasar a percibir por los mismos medios de pago la asignación familiar. Este traspaso ha implicado una mejoría en el nivel de recursos de estas familias" (CIFRA, 2010), situación que en 2014 implica un ingreso cercano a U\$S 75 mensuales por hijo menor de 18 años o por mujer embarazada. En este traspaso ha operado un cambio de paradigma de intervención estatal, desde la focalización a una tendencia a la universalización de la seguridad social.
} 
saber técnico evalúa como pobreza a aspectos individuales como las motivaciones, los valores y/o las actitudes (Ferguson, 1994: 178). Tales formas participativas no implican necesariamente la construcción de poder, puesto que este excede al logro de habilidades o capacidades y refiere a la apertura de ámbitos en los que los grupos sociales que son objeto de intervención estatal puedan asumir y tomar decisiones sobre su propio devenir, en un proceso que debería incluir la construcción y usufructo de derechos civiles que les permitan transitar una existencia plena en tanto ciudadanos (Colmegna, 2007: 138).

Esta cuestión conduce a Isla y Colmegna (2007: 1) a observar que para los grupos vulnerables "el desarrollo es una intervención totalmente dirigida desde afuera, contraria a la voluntad e interés de los actores beneficiarios. Esto sería el producto de pensar a la comunidad local en cuestión como un grupo a-histórico, sin agencia y entonces sin capacidad de expresar por sí mismo sus necesidades, intereses y conocimientos".

En el segundo caso, la experiencia en la producción de arroz agro-ecológico financiada por el Programa Nacional de Microcrédito para la Economía Social se desenvuelve a contracorriente de la inspiración de las políticas agrarias que han seguido $-\mathrm{y}$ en alguna medida continúan siguiendo- preceptos productivistas emanados de la Revolución verde e imbuidos desde las teorías de la modernización. Las intervenciones inspiradas en tales teorías — cuya expresión quizás más preeminente para el caso argentino tuvo lugar en la década de 1990 - han logrado entrelazar -y naturalizar - un componente asistencialista de las políticas sectoriales en un proyecto político neoliberal (desregulación, tercerización, reducción de la extensión industrial y rural, mercantilización del asesoramiento, las patentes y los insumos, etc.) (Alemany, 2008: 31) ${ }^{12}$. Se ha tratado de una toma de posición evidente, en la que las burocracias asumían sus tres roles, puesto que representaban sus intereses propios, expresaban su función de promotora de los objetivos de los sectores económicamente dominantes (agro-negocio, exportadores de granos y carnes, semilleras, laboratorios, etc.) y al mismo tiempo perseguían el cumplimiento de los objetivos que responden al interés general — mediado por visiones hegemónicas - de la sociedad en su conjunto (la necesidad de exportar para ingresar dividas con los que reducir los déficit comercial y fiscal).

\footnotetext{
${ }^{12}$ Desde ese enfoque, la posición que detentaban los productores agrarios más pequeños en la agenda pública era la de receptores pasivos de la denominada "ayuda social". De esto modo, eran excluidos de la producción, posibilitando su pervivencia a partir de subsidios estatales usualmente destinados a la generación de empleo temporal de baja productividad o a la producción de bienes y servicios con escaso valor agregado (Alemany, 2008: 3).
} 
Desde los enfoques postestructuralistas, advertibles en Argentina desde la salida de la convertibilidad ${ }^{13}$ las políticas de desarrollo comenzaron a preocuparse por atender aspectos sociales que las tornen cultural y económicamente viables, así como a considerar iniciativas y modificaciones realizadas por los grupos vulnerables que son objeto de intervención. De este modo, se pretende que los sujetos sociales implicados se involucren más allá de la etapa de diseño, participando en la gestión y en la evaluación de las iniciativas (Isla y Colmegna, 2005: 3). Lógicamente, esta afirmación no implica desconocer que en los propios contenidos de las políticas públicas de desarrollo de principios del siglo XXI pueden advertirse rastros de sinergias y contenidos expresados durante el auge neoliberal (por caso, tercerización de funciones, asistencialismo, clientelismo o verticalismo en la toma de decisiones). Aspectos que difícilmente puedan ser sustituidos de no mediar tiempo y constancia en la formación de quienes generan e integran las burocracias del desarrollo.

La articulación ministerial que ha forjado la política de desarrollo para el caso de la producción de arroz agro-ecológico en el norte de la Provincia de Santa Fe puede pensarse desde un enfoque post-estructuralista. La experiencia ha sido posible a partir de la vinculación inter-institucional entre la Comisión Nacional de Microcrédito (CONAMI ${ }^{14}$ del Ministerio de Desarrollo Social de la Nación, el Instituto de Investigación y Desarrollo Tecnológico para la Pequeña Agricultura Familiar de la Región Pampeana (IPAF Región Pampeana) del Instituto Nacional de Tecnología Agropecuaria (INTA) y la Subsecretaría de la Agricultura Familiar del Ministerio de Agricultura, Ganadería y Pesca. A partir de esta articulación se generó un proyecto productivo ligado con la tecnología social del microcrédito (Aguirre et al., 2010). El Programa Nacional de Microcrédito para la Economía Social provee de acceso al financiamiento a organizaciones sin fines de lucro con necesidades de capital para apuntalar sus emprendimientos. Además, contribuye con el fortalecimiento de las organizaciones sociales, de modo que el microcrédito se transforme en una herramienta para la inclusión social y la consolidación de una red de traba-

\footnotetext{
${ }^{13}$ Nos referimos a la caja de conversión peso argentino-dólar estadounidense mediante el establecimiento de una paridad fija que rigió la política monetaria del país entre abril de 1991 y diciembre de 2001. Las consecuencias más evidentes de esta política han sido el ingreso de capitales especulativos asociados a la fuga de divisas, la desestructuración del tejido industrial, el auge de importaciones, la primarización de las exportaciones y la pérdida masiva de empleos.

${ }^{14}$ En 2006 se sanciona la Ley 26.117 de Promoción del Microcrédito de Microcrédito para fomentar la Economía Social. Dicha disposición posee "como objeto la promoción y regulación del microcrédito, a fin de estimular el desarrollo integral de las personas, los grupos de escasos recursos y el fortalecimiento institucional de organizaciones de la sociedad civil que colaboran en el cumplimiento de las políticas sociales" (Art. 1, Ley 26.117). La legislación concibe al microcrédito como una herramienta de fortalecimiento de la Economía Social. Dicha Ley establece a la CONAMI como organismo público encomendado a dirigir microcréditos hacia las organizaciones sociales de productores para incorporar esta herramienta y fortalecerse a través de la gestión de fondos públicos (Aguirre et al., 2010: 38).
} 
jo $^{15}$. Se estima que en este marco más de 1.500 organizaciones sociales ligadas al microcrédito se articulan con organismos nacionales, provinciales y municipales para recibir capacitación y fondos para microcréditos ${ }^{16}$. Al reintegrar los microcréditos, los asociados permiten que el programa se sustente y que las organizaciones puedan intervenir sobre nuevas demandas sociales (CONAMI, 2014).

En este esquema de política de desarrollo, se identifica un intento de abordaje integral en torno a las problemáticas de los agricultores familiares del norte de la Provincia de Santa Fe, en el que 20 organizaciones representativas nucleadas en la Mesa de la Agricultura Familiar del área pueden direccionar los microcréditos en función de sus necesidades. De este modo, se ha producido una convergencia de iniciativas entre tres instituciones del Estado Nacional en el que se propende a potenciar la capacidad organizativa de los agricultores y a buscar alternativas de producción a través de las cuales mejorar su sustentabilidad económica. En esta articulación entre sociedad civil organizada y organismos estatales, se ha definido la potencialidad de la producción de arroz agro-ecológico para conservar el ambiente, generar trabajo e integrar a -en un principio 20- agricultores familiares que despliegan también otras actividades económicas. En esquemas como estos, puede advertirse que los vínculos entre sujetos sociales tenderían a generarse en un modo horizontal, en lo que podría calificarse como una experiencia post-estructuralista en el que la confianza de las propias organizaciones de agricultores se basa en relaciones de solidaridad y reciprocidad a partir de las cuales resulta posible una práctica de insumisión (Rist, 2002: 10). Una búsqueda de alternativas de estos frente a los sujetos sociales que decidían productos, calidades, precios y condiciones de venta - hasta directrices de políticas de desarrollo mediante su capacidad de presión-, llevándoles a adquirir recursos materiales y simbólicos para fortalecer las condiciones de vida. En esta búsqueda también se pone en discusión el espacio abstracto de las tecnocracias, considerando la reproducción de la vida en lugar de su mercantilización (Oslender, 2010: 97).

Al pensar en el poder en tanto relación, en experiencias como la recién citada nos encontraríamos ante procesos en los que pueden identificarse diferentes capacidades de cada sujeto social para imponer definiciones y decisiones al conjunto, aunque no por ello deben asumirse posturas simplificadoras, dicotómicas y/o absolutas al estilo opresores-oprimidos, a-temporales y a-espaciales. Las capacidades de

\footnotetext{
15 "En la medida en que estos emprendimientos se organicen y vinculen comercialmente y potencien su entramado social con procesos consolidados como el conjunto de cooperativas y mutuales, las fábricas recuperadas y las nuevas cooperativas de trabajo; además se encadenen productivamente con las PYMES, el movimiento sindical y demás actores [...] la fuerza política liberada por la Economía Social resulta sustancial" (Aguirre et al., 2010: 23) para afianzar un proceso de re-distribución de la riqueza en la Argentina.

${ }^{16}$ A octubre de 2014 la CONAMI (2014) ha otorgado 484.000 créditos por un valor cercano a U\$S 115 millones, con importes individuales cercanos a los U\$S 350 y grupales de U\$S 1.200.
} 
acción y decisión pueden modificarse de acuerdo a las circunstancias, a los polos que establezcan una relación y a los recursos — simbólicos y materiales- de los que cada parte dispone.

Los grupos sociales sobre los que las intervenciones públicas pretenden incidir poseen capacidad de acción y algún margen de decisión para avalar, modificar, proponer o bien resistir su implementación. Negar u omitir esta situación conllevaría a desestimarlos como sujetos políticos. Incluso, las definiciones de tales grupos pueden adquirir relativa autonomía de las decisiones de los intermediarios. En los procesos sociales implicados en las políticas de desarrollo, los intermediarios precisan de apoyo político de los sujetos de la intervención, puesto que sin ese respaldo dejan de detentar poder en el seno de una vinculación determinada (Colmegna, 2005: 130).

Cuando señalamos que el poder resulta viable mediante el control y direccionamiento de flujos de energía e información que atraviesan, posibilitan y/o desactivan una relación (Raffestin, 1993; Foucault, 2003), debería considerarse también los roles que juegan los intermediarios (técnicos, administrativos, extensionistas, referentes y militantes sociales) en las políticas de desarrollo. En esta dirección, coincidimos con Colmegna (2005: 130) cuando advierte que intermediarios como los citados no ejercen un poder "absoluto". La forma en la que circula el poder por las redes en las que los recursos simbólicos y materiales se distribuyen resulta cambiante y multi-direccional.

\section{Reflexiones finales}

La inquietud que ronda en torno a este escrito es, como siempre, qué hacer con las intervenciones de desarrollo. Como hemos esbozado, el qué hacer debería estar precedido por el cómo, el dónde, el cuándo, el para qué y el para quién/es. En esta dirección, Argentina - y América Latina en general- cuentan con una vasta y rica experiencia reciente, aunque a nuestro juicio escasamente sistematizada, de lo que las agendas públicas populistas -en alguna medida rupturistas de la cosmovisión neoclásica que predominó en el último cuarto de siglo $\mathrm{XX}$ - pueden señalar en torno a la re-definición de nociones.

La discusión y re-definición de nociones como espacio, poder y desarrollo debería trascender a la Academia, involucrándola decididamente en una estrategia de vinculación con las burocracias, a fin de incidir en el diseño y direccionamiento de las políticas de desarrollo. En definitiva, entendemos que los aportes de dichas nociones abordan problemáticas más enriquecedoras que las que usualmente su utilización a-crítica posibilita. El espacio es más que una construcción social, el poder es más que el Poder del Estado y el desarrollo encierra más aportes que su reducción a crecimiento con inclusión vía aumento de la producción. En primer lugar, la noción de espacio permite comprender el hecho de que las distribuciones 
espaciales y las diferenciaciones geográficas pueden ser el resultado de los procesos sociales, aunque también condicionan el funcionamiento de tales procesos. En segundo término, la noción de poder posibilita el análisis de relaciones y prácticas. El poder se liga con la manipulación de los flujos que atraviesan, posibilitan, complejizan y/o desactivan una relación, se trata de energía e información. En tercer lugar, desde una perspectiva post-estructuralista, las intervenciones de desarrollo podrían incluir la construcción y usufructo de derechos civiles que permitan transitar a quienes son su objeto una existencia plena en tanto ciudadanos.

En la medida que las burocracias estatales ligadas a las problemáticas del desarrollo actúan a través de intervenciones que responden a cosmovisiones diversas y hasta contradictorias - usualmente superpuestas por sedimentación temporalresulta arduo un debate conceptual que clarifique posiciones y alumbre posibilidades. Ello parece crucial a la hora de exponer, para las distintas burocracias, sus roles sectorial - al asumir la representación de sus intereses-, mediador - al garantizar los intereses de los sectores económicamente dominantes- e infraestructural -al buscar el cumplimiento de los objetivos que responden al interés general一. En el análisis de estos roles podría recuperarse la noción de "arena de conflicto", en la que puedan quedar evidenciadas para las intervenciones de desarrollo las distancias perceptibles entre lo escrito y lo tácito, entre los aparentes y los efectivos beneficiados así como entre los usos y abusos realizados en torno a las nociones.

\section{Bibliografía}

Aguirre, Lizette; Caballero, Luis; Deluca, Laura; Dumrauf, Sergio; Gandulfo, Alberto; Hall, Marcos; Justianovich, Sergio; Laurnagaray, Ricardo; Olmos, Elisabet, y Tito, Gustavo (2010) Microcrédito, tecnología y gestión asociada en la agricultura familiar. Buenos Aires: Ministerio de Desarrollo Social de la Nación. Alemany, Carlos (2008) "Volvió la extensión... iy se armó la discusión!", en R. Thornton y G. Cimadevilla (comps.) Grises de la extensión, la comunicación y el desarrollo. Buenos Aires: INTA: 27-50.

Blanco, Jorge (2007) "Espacio y territorio: elementos teórico-conceptuales implicados en el análisis geográfico", en M. V. Fernández Caso y R. Gurevich (coords.) Geografía, nuevos temas, nuevas preguntas. Un temario para su enseñanza. Buenos Aires: Editorial Biblos, 37-60.

Butler, Judith (1997) Lenguaje, poder e identidad. Madrid: Editorial Síntesis.

CELS (2007) Programa familias por la inclusión social. Entre el discurso de derechos y la práctica asistencial. Buenos Aires: CELS.

CIFRA (2010) La asignación universal por hijo a un año de su implementación. (Documento de trabajo 7). Buenos Aires: CTA.

CONAMI (2014) Organismos descentralizados: la Comisión Nacional de Microcrédito. Ministerio de Desarrollo Social de la Nación. [Puesto en línea el 11 de 
septiembre de 2008. URL: <http://www.desarrollosocial.gob.ar/conami/120>. Consultado el 13 de noviembre 2014].

Claval, Paul (1982) Espacio y poder. México: Fondo de Cultura Económica.

Claval, Paul (2002) "El enfoque cultural y las concepciones geográficas del espacio". Boletín de la A.G.E., 34, 21-39.

Colmegna, Paula (2005) "Una etnografía de políticas públicas: el caso de los PAGV”, en A. Isla y P. Colmegna (comps.) Política y Poder en los Procesos de Desarrollo: debates y posturas en torno a la aplicación de la antropología. Buenos Aires: FLACSO, 113-149.

Comeliau, Christian (1997) "Los retos de la globalización". Perspectivas. Revista trimestral de educación comparada, 1, 27-32.

de Souza Silva, José (2009) La Farsa del "Desarrollo". Del colonialismo imperial al imperialismo sin colonias. San José: Editorial Universidad de Costa Rica.

Escobar, Arturo (2005) "El «postdesarrollo» como concepto y práctica social", en D. Mato (coord.) Políticas de economía, ambiente y sociedad en tiempos de globalización. Caracas: Facultad de Ciencias Económicas y Sociales, Universidad Central de Venezuela, 17-31.

Esteva, Gustavo (2000) "Desarrollo", en A. Viola (comp.) Teoría y estudios etnográficos en América Latina. Barcelona: Paidós, 67-101.

Fair, Hernán (2010) "Una aproximación al pensamiento político de Foucault". Polis, $1,13-42$.

Ferguson, James (1994) "The Anti-politics machine. «Development» and bureaucratic power in Lesotho". The Ecologist, 5, 176-181.

Fernández, Ramiro; Güemes, María Cecilia, y Magnin, Juan Pablo (2007) "Buscando los «puentes perdidos» del nuevo regionalismo. Dinámicas productivas y calidad socioeconómica territorial". Cuadernos del CENDES, 65, 63-93.

Foucault, Michel (1980) "El ojo del poder, Entrevista con Michel Foucault", en J. Bentham, El Panóptico. Barcelona: Ediciones La Piqueta, 1-18.

Foucault, Michel (1986) La Voluntad de saber. Bogotá: Siglo XXI.

Foucault, Michel (2003) Vigilar y castigar. Buenos Aires: Siglo XXI.

García, Ariel, y Rofman, Alejandro (2013) "Poder y espacio. Hacia una revisión teórica de la cuestión regional en Argentina". Problemas del desarrollo. Revista Latinoamericana de Economía, Universidad Nacional Autónoma de México, $175,101-124$.

Haesbaert, Rogério (2013) "Del mito de la desterritorialización a la multiterritorialidad”. Cultura y representaciones sociales, 15, 9-42.

Harvey, David (2014) Diecisiete contradicciones y el fin del capitalismo. Quito: Editorial IAEN.

Isla, Alejandro, y Paula Colmegna (2005) "Política y cultura en las intervenciones de desarrollo", en A. Isla y P. Colmegna (comps.) Política y Poder en los Procesos de Desarrollo: debates y posturas en torno a la aplicación de la antropología. Buenos Aires: FLACSO, 1-38. 
Isla, Alejandro, y Paula Colmegna (2007) "La importancia de la cultura y la política en los procesos de desarrollo". Revista MAD, 16, 93-107.

Lefebvre, Henri (1974) "La producción del espacio". Papers: Revista de Sociología, 3, 219-229.

Lobato Correa, Roberto (2000) Região e organização espacial. São Paulo: Editora Ática.

Massey, Doreen (2012) "Introducción: la geografía importa", en A. Albet y N. Benach (comps.) Doreen Massey. Un sentido global del lugar. Barcelona: Editorial Icaria.

Oslender, Ulrich (2010) "La búsqueda de un contra-espacio: ¿hacia territorialidades alternativas o cooptación por el poder dominante?" Geopolítica(s), 1, 95-114.

Oszlak, Oscar (1976) "Notas críticas para una teoría de la burocracia estatal", en Teoría de la burocracia estatal: enfoques críticos. Buenos Aires: Editorial Paidós.

Oszlak, Oscar (2006) "Burocracia estatal: Política y Políticas Públicas”. Revista Postdata, 11, 11-56.

Raffestin, Claude (1993) Por uma geografia do poder. São Paulo: Ática.

Ribeiro, Gustavo Lins (2007) "Poder, redes e ideología en el campo del desarrollo". Tabula Rasa, 6, 173-193.

Rist, Gilbert (2002) El desarrollo: historia de una creencia occidental. Madrid: Libros de la Catarata.

Rostow, Walter (1961 [1947]) Las etapas del crecimiento económico. México: Fondo de Cultura Económica.

Ruíz López, Domingo, y Cádenas Ayala, Carlos (2004) “¿Qué es una política pública?". IUS. Revista Jurídica, 18, 43-49.

Santos, Milton, y Silveira, María Laura (2004) Brasil. Território e Sociedade no inicio do século XXI. Rio de Janeiro: Bertrand.

SID (1968) "The Green Revolution: Accomplishments and Apprehensions". Discurso de William Gaud. [Puesto en línea el 23 de marzo de 2004. URL: <http://www.agbioworld.org/biotech-info/topics/borlaug/borlauggreen.html>. Consultado el 17 de octubre de 2014].

Silveira, María Laura (2006) "Espejismos y horizontes de la geografía contemporánea". Revista Párrafos Geográficos, 1, 1-22.

Slater, David (2000) "Precisando el siglo americano. Temas para una perspectiva poscolonial". Revista Nueva Sociedad, 166, 134-148.

Slater, Fernando (1999) "Las etapas del crecimiento económico de Rostow. Consideraciones sobre el evolucionismo como modelo interpretativo". Revista Soñando el sur, 2, 114-121. 